\title{
EL SUEÑO DE LAS MÁQUINAS. REFLEXIONES EN TORNO A LA OBRA DE GÜNTHER ANDERS ${ }^{1}$
}

A dream of machines. Reflexions on Günther Anders work

\section{Breno Onetto Muñoz*}

Una de las grandes demandas del conflicto bélico contemporáneo, llevado a cabo por los EE.UU., guarda relación con el uso eficiente de armas ultramodernas o de alta tecnología, como apoyo militar, pero requeridas sobre todo para la nueva guerra contra el terrorismo al final de la guerra fría; conflicto que se muestra y se materializa en la forma de los ataques virtuales, pero realmente efectivos que realizan seudopilotos o mejor dicho: funcionarios de la defensa norteamericana por medio de drones, o bombarderos no piloteados, dirigidos a distancia desde el territorio estadounidense al país o al eje maligno de turno que EE.UU. desea combatir, en el control que lleva hace largo tiempo a cabo del espacio y territorio geopolítico mundial. Aviones capaces de realizar la cacería de hombres o enemigos de manera muy exitosa, exacta y eficiente, y sin necesidad de una cercanía mayor entre ambos que la del trabajo realizado desde los cuarteles u oficinas de comando respectivas. Thomas de Maizière, actual ministro de defensa alemán, ha dicho de esta inquietante guerra secreta llevada por el país del norte que, si bien la mayoría de los alemanes se encuentra a favor de ella (el $61 \%$ apoya y justifica la vigilancia de la sociedad por el FBI y la CIA norteamericana, y esto por razones exclusivamente de seguridad); los actuales ataques de unidades especiales (por ejemplo a Bin Laden en Pakistán) y drones (Irak, Afganistán), la guerra secreta y minúscula llevada a cabo por el gobierno de Obama, sin gran apoyo de los futuros electores pero sí de efecto inmediato, hasta en los lugares de más difícil acceso, "la considero algo falsa, errada". Pues "lo que pasa allí es asesinato, lucha, medidas relativas, escrúpulos, culpa, faltas, y resultados. Y eso, al decir del ministro alemán, debe ser discutido y resistido por los soldados y no sucederse en cualquier sitio silencioso y calmo en un continente diferente" ${ }^{2}$.

El ejemplo puesto aquí lo planteo como una forma y la necesidad de apuntalar algunas de las ideas arrojadas por el filósofo Günther Anders en su texto editado en dos volúmenes: "La obsolescencia del hombre" (1956/1980), obra central de su pensamiento que expone en cierta forma sus ideas más fuertes sobre los efectos psicológicos (seelenhaft) producidos en el alma humana en el mundo

\footnotetext{
${ }^{1}$ Texto leído en la jornada sobre "Günther Anders, pensador radical de la era tecnológica". Facultad de Filosofia y Humanidades, Universidad Austral de Chile, el 7.09.2012.

${ }^{2}$ Entrevista emitida por el canal 2 de la señal de televisión alemana, Zweites Deutsches Fernsehen, ZDF, el 3.9.2012.
} 
técnico como en el de la era atómica en la que nos hallamos, pero donde se sugieren de igual manera planteamientos de fondo de estricto rigor para una ética y una política para los tiempos actuales, asuntos por tanto no meramente derivados, sino también principales en vista del orden técnico mundial que nos gobierna. La energía atómica y la técnica, la imagen técnica y los medios, las febriles automatizaciones del mundo productivo, los mega (macro) y microsistemas de producción del mundo son los temas y nudos problemáticos que se nos están tornando impostergables, si es que alguna vez no lo fueran.

La amenaza y fascinación provocada por los nuevos aparatos técnicos (a los que, en efecto, nos hallamos destinados pero también entregados) y el mismo sistema técnico, han ido, paradójicamente minimizando y disminuyendo su impacto casi de forma exclusiva debido a que sus efectos nocivos se han ido cubriendo y hasta borrando, o bien, se hallan simplemente ocultos a la opinión pública de un modo políticamente intencional y manifiesto. Es lo que está pasando en la época contemporánea (piénsese tan solo en los accidentes nucleares más críticos vividos en los últimos 40 años por la humanidad y que se han traducido en enormes derrames de material radiactivo ocurridos producto del colapso nuclear en los ya históricos reactores atómicos de Three Mile Island (EE.UU.: 28.3.1979), Chernóbil (URSS: 26.4.1986) y Fukushima (Japón: 11.3.2011) y el porqué de su apresurada invisibilidad debido a la rápida minimización y ocultamiento del daño causado) y que parece dejarnos muy pronto insensibles en nuestra conciencia colectiva, haciendo inaudible el peligro, la amenaza de la técnica moderna tanto a nivel público, esto es, a nivel político, donde corre cada vez más solapada y en silencio; pero también a nivel privado donde no se la consiente, sino únicamente cuando cobra un numero visible de víctimas, cual desastre natural, logrando así notoriedad y otra vez salir en la noticia; pero solo hasta ser silenciada de nuevo por la siguiente noticia, dejándonos ciegos a cualquier alarma atómica u otro peligro técnico inminente. Desde el lanzamiento de las bombas, lo que siguió no ha sido más que la continuación de una carrera y estrategia armamentista en la que se ha buscado equilibrar dos potencias militares: por un lado, los países capitalistas y, por el otro, los del socialismo real; favoreciendo la proliferación de armas los primeros, por supuesto, con el pretexto de garantizar la paz de un mundo libre. Y si agregamos a ello la introducción en la época de posguerra del uso pacífico de esta energía, que buscaba suplir las energías eléctricas faltantes de EE.UU. y Europa, el mundo en su conjunto no ha puesto ningún obstáculo al avance de la investigación y tecnología nuclear, haciendo caso omiso o desviando la mirada ante cualquier factor que pudiese ser óbice para su desarrollo. Porque en las nuevas medidas y estrategias del progreso y de desarrollo tecnológico, los nuevos medios de comunicación masivos andan siempre detrás de noticias mucho más seductoras que las opiniones que pudieran comprometer una reflexión más compleja y ardua de todo el sistema que mueve a nuestro mundo occidental; y de allí que la propaganda suya sepa destacar los logros y avances técnicos del presente y del porvenir, dejándonos asimismo 
sordos e indiferentes frente a los incalculables e inimaginables efectos de los mismos, y sustraerle así cualquier reflexión crítica más de fondo a los descubrimientos técnicos o a sus posibles defectos y posibles amenazas para la humanidad.

Por cierto que por "técnica" habría que entender, en el presente, sin duda, "a la totalidad de los dispositivos y procesos requeridos tanto para la utilización y acceso a los recursos naturales de energía y de materias primas, así como el empleo práctico de los conocimientos científico-naturales para la emancipación civilizatoria de las necesidades del hombre" (Dries, Technik als Subjekt der Geschichte, 54). La técnica de la antigüedad clásica era sin embargo otra cosa: lo que podemos llamar téchne, era un talento capaz de cierta virtuosidad, una destreza capaz de acabar o de perfeccionar algo, y en tal sentido capaz de un elevado rendimiento en su acción; se trataba de un saber/un conocimiento que complementaba a los otros productos, acciones presentes en el mundo, enteraba a la naturaleza (Aristóteles); y servía a esta sin peligro, ni agresión en contra suya. Desde el nacimiento del actual mundo técnico caracterizado por las máquinas, el sistema de aparatos, el mundo se ha tornado abiertamente más peligroso, un riesgo latente, falto casi de manera absoluta de toda previsibilidad; pues no somos capaces de imaginar siquiera o representarnos totalmente los efectos de los productos que somos capaces de producir. Hemos hecho de nuestra vida en la tierra, de nuestro mundo un lugar de peligro y de amenaza constante, por nuestros inventos $\mathrm{y}$ aparatos, pero nos hemos vuelto firmemente también incapaces de sentir y de imaginar (unos analfabetos de la emoción, de la intelección). El impacto de la técnica sobre el hombre y su naturaleza frágil y mortal, precisa diferenciarla por su forma cambiante frente a la natura engendrada y natural del hombre, frente a su mortalidad lo ha comenzado a alienar casi sin darse cuenta. La técnica no buscaba como hoy el sometimiento de la naturaleza, sino el empleo cuidadoso de ella, su extensión, ampliación. En la temprana modernidad esto se revierte dramáticamente. Ella se asocia a las ciencias naturales y se transforma en una irrefrenable dinámica de desarrollo cuyo objetivo final no es más la vida buena o bella, en armonía con la naturaleza, sino el dominio de la naturaleza, y extensión del poder del hombre. Es más, durante el desarrollo industrial del siglo XIX se anudaron de una manera muy fuerte las ciencias naturales, la técnica y las ingenierías, con el sistema económico capitalista lo que provocó el auge y bienestar de amplias capas de la población y que trajo una enorme tecnificación de la vida cotidiana. Pero donde también aparecieron los inesperados riesgos, pues los aparatos y procedimientos técnicos se muestran desde entonces como factores/causas de molestias/trastornos (la caída/bajas de la luz), en parte también como amenazas para la vida humana (como los reactores atómicos). El optimismo del progreso de los últimos años y la representación del hombre como el soberano dominador científico técnico de la naturaleza es un hecho de la modernidad más reciente. También la filosofia ha ido encontrando en la técnica un problema a descifrar, y reacciona creando una disciplina propia: la filosofia de la técnica. 
Si la diferencia entre el hombre y sus artefactos hasta el siglo XIX lo constituía la libertad del primero; la libertad de poder elegir y establecer objetivos para el hombre, escogiendo, decidiendo sobre los medios para su realización; y de ese modo, los efectos y las acciones para sus fines estaban aún bajo su control, lo que vivimos hoy no hace sino cuestionar en la filosofía de la técnica, si acaso y hasta qué punto todavía pueda ser entendido el ser humano como un sujeto de la técnica o de sus técnicas. La obra de Anders lo sabemos ya niega esta posibilidad, afirmando su contrario: en el siglo XX es la técnica la que se ha vuelto, y cambia el sujeto de la historia, es ella la que se ha convertido en el poder político y social dominante, volviendo al hombre en un ser "obsoleto", que cojea detrás de sus criaturas técnicas. En el centro de la obra de Anders se halla, por lo tanto, la "transformación del alma humana", del ser del hombre por medio de sus propios productos. Describir ese mundo técnico y sus modificaciones actuales ha sido la tarea más crítica y radical que este filósofo se propusiera desarrollar (Dries, Günther Anders, 10).

\section{ANDERS Y EL ESTATUTO DE LO TÉCNICO}

Para Anders vivimos en el umbral de una época incapaz de representarse (o imaginarse y sentir o incluso tener "verdadera" conciencia moral de) los efectos de la catástrofe atómica; incapaz de sentir un dejo de miedo o angustia real y efectiva ante la amenaza concreta, ya vivida, y que nos acecha de manera flagrante en cada "accidente" nuclear. Nuestra "ceguera atómica", como la llamase él mismo, no es una falla de nuestra incapacidad física inmediata, sino el resultado de una desproporción, un desfase o desnivel de nuestro ser con el mundo técnico, el desnivel prometeico (das prometheische Gefälle) en que nos hallamos los hombres en tanto que hombres, e histórica, respecto de nuestros mismos productos técnicos. Pues los aparatos técnicos no son solo "medios" para el hombre, como se suele pensar desde la discusión habitual. El hombre, como piensa Günther Anders, en su obra mayor "La obsolescencia del ser humano" (que es un signo característico de la sensibilidad de nuestra época), no está ya más a la altura de sus productos, es más, incluso los pensamos en categorías erróneas como las de medios y fines. La bomba atómica de hoy, la planificada por las nuevas potencias nucleares (India, Pakistán o Irán) no es simplemente un medio, pues su efecto ha superado ya todo posible fin imaginable (effectus transcendit finem); y puesto que esto ya pondría en tela de juicio toda otra definición de fin, haría volar una tal categoría. La invención, el hecho mismo de la bomba ha hecho suspender ya el sentido mismo de la posibilidad de continuación de la historia. Incluso si se buscase la destrucción total del mundo (como es el caso de Eróstrato) esa arma final se habría convertido de la consideración material cuantitativa específica en una cualitativa mucho más determinante de lo que sabemos, y que nos deja expuestos a una situación extrema: ante la posibilidad de destrucción total del género humano, incluso aunque no se fabricasen más armas nucleares. Pero el tema, para Anders, aquí, es el desnivel 
alcanzado actualmente por la técnica (Anders, Filosofia de la situación, 66-74) y que deja al hombre sin la capacidad, o la facultad precisa de representación, de la conciencia moral, ni de la plasticidad del sentimiento humano para enfrentar acontecimientos del tamaño de cualquier genocidio o de la destrucción masiva de material humano por la fabricación tecno-industrial programada de cadáveres (Heidegger, Bremer, 56) en la primera mitad del siglo XX.

Las facultades del hombre no le garantizan identidad alguna siquiera, pues se encuentran tan distanciadas unas de otras que ya ni se ven, y si ya que no se ven no se tocan, porque no se enfrentan ni se hacen daño. Hemos alcanzado "la época de la deshumanización más grande" de todas, porque al menos, antes, deseo y razón luchaban en un mismo individuo, sus contradicciones no alcanzan casi a conocerse. El hombre se encuentra atomizado en un sinnúmero de diferentes funciones o roles que debe desempeñar: lo que hace o produce aquí, lo que siente allá, esto es, como productor o individuo sensible. Nos hemos ido transformando, en esta sociedad moderna, en un individuo dividido, en un divisum-dirá el filósofo (Anders, Die Antiquierheit, 135ss): una sociedad que hizo posible la existencia de funcionarios como Adolf Eichmann, seres que podían desempeñar las funciones de buen padre de familia, pero también las de un perfecto empleado de un régimen totalitario capaz de ejecutar sin ninguna contradicción la más eficiente administración de un campo de exterminio. Y siendo esto así, lo único que le queda por hacer a nuestra humanidad, hoy, es: "educar la fantasía moral, en el intento de superar el desnivel, de ajustar la capacidad y la elasticidad de nuestra imaginación y de nuestros sentimientos" (Anders, Filosofia de la Situación, 70) a la altura o a la dimensión de nuestros propios productos; a la dimensión imprevisible y titánica de lo que podemos producir y provocar con ellos, de manera de armonizar las capacidades humanas de imaginar y sentir, o equilibrar todas las facultades del alma (de acuerdo con Kant) en un solo agente e individuo no escindido esquizofrénicamente. Lo que se trata de evitar es que el mundo técnico, el mundo desplegado por el ser humano en la fabricación de aparatos técnicos y el complejísimo megasistema armado de lo técnico sea ahora el que nos provoque o demande el ajustarnos a su dimensión, y por ello, la contrafuerza para esa cuerda solo puede ser el aumentar, como sea, la capacidad de imaginar para resistir y saber de algún modo lo que cada cual está haciendo y siendo en este mundo. Y si ello es posible, no lo será especulando metafísicamente en demasía, pues ahora no se busca tanto superar una trascendencia que se halla más allá del mismo sujeto, sino extender al máximo sus posibilidades inmanentes para sobrepasar su desnivel.

La crítica a la técnica de Anders va siempre de la mano con esa máxima que habla sobre la discrepancia entre lo que podemos hacer y lo que nuestra imaginación nos permite representarnos de todo aquello. Si nuestra razón parecía limitada para un Kant, nuestra imaginación ilimitada de antaño se ve hoy todavía más limitada ante la producción técnica moderna, y lo mismo le sucede incluso a nuestra capacidad de sentir y de responsabilizarnos efectivamente por nuestros actos. La imaginación 
(nuestra peculiar sensibilidad) es incapaz ya de enfrentar hoy los efectos de los actos más extremos perpetrados por el hombre, si no ¿a quién habría de hacer responsable de la muerte de 200.000 individuos en Nagasaki? ¿Al piloto del bombardero, a Truman, presidente de los EE.UU., a su pueblo? Uno de los pilotos, aunque no el que soltase la bomba, propiamente, quiso asumir su responsabilidad en el acto y no tardó mucho en ser recluido, declarado interdicto en un hospital psiquiátrico al insistir en su culpa y realizar robos de poca monta para conseguir un castigo, ante la necesidad suya de ser castigado. El gobierno no entendía aquella contradictio ad termini, este sujeto había sido condecorado con medalla de héroe de guerra, pero el piloto en un acto único hasta más que humano, porque incomprensible, de una culpabilidad derogada, buscaba a toda costa un castigo, una pena, un dolor sensible ante un crimen no reconocido, sino solo por él mismo. ¿Cómo podía alguien querer dolerse por doscientos mil enemigos, 200 mil seres humanos?

Lo que la obra de Anders hace entonces es señalar hacia una transformación efectiva del alma del hombre en la relación que este tiene con la técnica, en la era de la segunda época industrial; y ese cambio no es ningún cambio relacionado con nuevos mecanismos en las fuentes de producción económicas o en las fuentes energéticas de la producción, ni la forma de organizarse (dígase taylorismo) o el tipo de maquinaria que la nueva era esté utilizando. Este mismo sentido es el aludido por Heidegger cuando afirma que la esencia de la técnica no es nada técnico: la muerte masiva de miles, el dolor de innumerables ha desplazado la muerte del hombre como tal, su mortalidad se aleja y oculta alejándonos toda cercanía esencial (Heidegger, Bremer, 60).

La revolución industrial va a ser considerada como tal cuando el principio de la máquina se torne algo reiterativo e insistente, a saber, justo en el instante cuando la reproducción de las máquinas esté asegurada por otras máquinas. La técnica se torna dominante cuando el principio de la máquina es interiorizado por el hombre, cuando su conciencia se torna aparática, cuando el sistema del objeto técnico es atrapado por el alma del hombre, en la época moderna de la segunda revolución industrial como reza el subtítulo de la obra principal del filósofo; cuando la fabricación de un producto se convierte en medio de producción de otra y la nueva producción de otros más, y así hasta el infinito. El mismo hombre ha entrado ya al engranaje productivo (de sí mismo: en la clonación) y deviene medio de producción (pieza útil para la ingeniería humana: banco de órganos), o mercancía (en los concursos). La técnica impone así condiciones materiales para esa metamorfosis del alma humana, a las que el hombre se va adecuando o se pliega para salvarse de ser considerado ya como mero residuo, o un factor molesto en la producción, un Störfaktor, como afirmara Heidegger, en otro lugar, respecto del material humano referido técnicamente (para la industria técnica química o la genética). Todo lo cual ha llevado al hombre a quedar obsoleto ante la relevancia y énfasis que él mismo ha otorgado al aparato técnico. Solo que el sistema técnico o la cadena desarrollada por la técnica moderna, en su historia, había ido 
dejando al hombre al comienzo del sistema, como inventor, científico y trabajador manual; pero hoy es visible al final como un consumidor de aquello mismo que produce. Donde todo el proceso productivo se ve deshumanizado por la mecánica y las leyes del funcionamiento. Anders evita con el tema maquinal, con lo maquínico se podría decir, plantear el análisis de esta sociedad de consumo desde parámetros ideológicos o de una sociología, convirtiendo su análisis en una vuelta de tuerca más dentro de la lógica procesual y maquinal: la acumulación de productos, luego, debe crear la necesidad de estos para seguir produciéndolos. Se precisa así producir la necesidad. Anders anota, por entonces que: se producen guerras para las armas, la técnica de punta se prueba notoriamente en la última guerra de la época; y lo hace siempre, como lo muestran varios films del director turco-alemán Harun Farocki, primero como maquinaria de guerra, para luego ir a dar en sus miras, invenciones y aparatos, a la industria de la agricultura o de la robótica industrial, y de la automatización en general.

Para encontrar el lugar del hombre, su relevancia ante el objeto técnico, esto supone volver a mirar a donde queda relegada su presencia, tras el embate transformador de lo técnico; en breve esto significa perfilar crítica y de manera consciente el espacio humano dado por esta técnica, en Anders. Por ello ha de decirse que el rasgo fundamental de este cambio del alma en la época de la segunda revolución industrial, en la época de la técnica moderna como solemos entenderla (desde Heidegger, como permanente interlocutor en este análisis), viene dado por la "vergüenza prometeica" (prometheischer Scham): que es el sentimiento que el filósofo ha puesto en el hombre moderno, el que descubriendo su desnivel producto de su hacer y representar, descubre a la vez una vergüenza en su propia naturaleza u origen porque es algo incalculable y ancestral, el hombre mismo proviene de un proceso ciego, que es distinto del producto fabricado por la máquina que es preciso y exacto, actualizable como mejorable y siempre reproducible; contrario es nuestro caso, nuestro ser es perecedero, torpe y rígido, poco actualizable y falible. Para escapar a la vergüenza prometeica, entretanto, el hombre ha comenzado a reificarse (Verdinglichung), primero, al compararse y tratar de equiparar la distancia con el producto fabricado el hombre moderno se cosifica y se pasa luego al campo de los aparatos y máquinas, maquillándose, p.ej., para cuidar de su apariencia; en segundo lugar: transforma su cuerpo mediante técnicas de ingeniería humana (human engineering) para intentar mantenerlo en forma y función (De Vicente Hernando, Günther Anders, 218); del mismo modo, busca eternizar su ser recurriendo a la iconomanía, procurándose una cantidad y acumulación suficiente de imágenes para experimentar su mundo. El segundo rasgo del cambio del hombre en esta época lo dijimos más atrás es que: aquello que puedo producir excede o ya va más allá de mi capacidad de representación; $\mathrm{y}$ en tercer lugar: no hacemos experiencia de la totalidad del mundo ni vamos como antaño hacer una experiencia o salida hacia el mundo, sino que nos contentamos con un símil, hemos cambiado el mundo real por el de la tv, la 
radio (hoy en día tendríamos que incluir también a todas las redes sociales del ordenador) por fantasmas de realidad que le abastecen la falta de mundo, y por los que se fragmenta; y por último: existiría para Anders entre otras dimensiones de la desproporción prometeica, un desnivel incluso en aquello que podemos producir y lo que podemos usar, así como también lo hay entre lo máximo que podemos producir y el máximo de lo que podemos necesitar. Estas son finalmente las grandes o centrales cuestiones que en el funcionamiento sistemático de los aparatos, la técnica como tal entrega a pensar y debe hacernos reflexionar, una alerta a un sueño que se hace realidad y que no siempre pasa por hacerse consciente en todo su delicado espesor.

Universidad Austral de Chile* Campus Isla Teja, Valdivia (Chile)

brenoonetto@uach.cl

\section{OBRAS CITADAS}

Anders, Günther. La obsolescencia del Hombre. Barcelona: Editorial Pre-textos, 2011, 2 vols.

-------Filosofia de la situación. Edición de César de Vicente Hernando. Madrid: Los libros de la catarata, 2007a.

-------Estado de necesidad y legítima defensa (Violencia sí, o no). Edición de César de Vicente Hernando. Madrid: Centro de Documentación Crítica, 2007b.

-------Die Antiquierheit des Menschen. München: Beck, 1956/1980, 5ª edición de 2002 (se cita a o b según el volumen usado).

------Über Heidegger. Editado por Gerdhard Oberschlick. Con Prólogo de Dieter Thomä. München: Beck 2001.

-------Llámese cobardía a esa esperanza. Entrevistas y declaraciones. Prólogo de Ma. Elena Rubio, Bilbao: Besatari, 1995.

De Vicente Hernando, César. Günther Anders. Fragmentos de Mundo. Introducción a la obra de Günther Anders. Madrid: La oveja roja, 2010.

Dries, Christian. Günther Anders. Profil. Paderborn: Fink-Verlag, 2009.

------ Technik als Subjekt der Geschichte? Technik- und Gesellschaft-philosophie bei Günther Anders. Tesis de Magister Artium, Albert-Ludwig-Universität Freiburg 2003/4.

Heidegger, Martin. Bremer und Freiburger Vorträge. (Einblick in das wasist, Bremer Vorträge 1949; Grundsätze des Denkens, FreiburgerVorträge 1957). GA.77. Frankfurt am Main: Vittorio Klostermann, 1994. 